Kurt A. Strasser*

\title{
Visions of "Eco- Law": A Comment on Capra and Mattei, The Ecology of Law: Toward a Legal System in Tune with Nature and Community (Berrett-Kohler Pubs., 2015)
}

DOI 10.1515/ael-2016-0058

Abstract: This new book offers an interesting vision of a new legal system, one aimed at promoting sustainable living on the planet. The vision is supported with an interesting and rich discussion comparing the history of scientific thought to the history of legal thought, noting that legal thinking has not yet evolved from mechanistic traditional individual rights centered thinking to a focus on networks and relationships. Yet it needs to do so to move to a new conception of "eco-law" which will support sustainable living and regeneration of the ecosystem. The vision is appealing and the presentation effectively sets the stage for further discussion. Eventually more will be needed to support the adoption of a new "eco-law" vision.

Keywords: sustainability law, scientific thought, jurisprudence, eco-law

\section{Table of contents}

1 Eco-Law

2 Science and law: Changing conceptual paradigms point toward eco-law

3 Conclusion

References

Perspectives on 'The Ecology of Law' by F. Capra and U. Mattei

1. "Visions of 'Eco- Law': A Comment on Capra and Mattei, The Ecology of Law: Toward a Legal System in Tune with Nature and Community (Berrett-Kohler Pubs., 2015)” by Kurt A. Strasser, https://doi.org/10.1515/ael-2016-0058

2. "If nature were a Commons would the homo economicus be a rational agent dropped in an evolutionary trap or an ignorant pedantic? A Note on Ecology of Law. Toward a Legal System in Tune with Nature and Community, by F. Capra and U. Mattei, 2015” by Mauro Gallegati, https://doi.org/10.1515/ael-2016-0015

*Corresponding author: Kurt A. Strasser, University of Connecticut Law School, St Petersburg, FL 33701, USA, E-mail: kstrasser65@gmail.com 
Life on the planet as we now know and enjoy it depends on crucial support from the ecosystem. Yet our lifestyle is placing dramatic stress on these crucial support systems. We consume the support of the ecosystem of about one and one-half earths world-wide; the most consumptive developed societies consume at a pace that would require three to five earths if everyone consumed this way. ${ }^{1}$ Further, we are changing the climate in ways that will make it less hospitable to humans as we live today, creating further stress and inbalance. And we are responsible.

In our current age, rightly labeled the "anthropocene", humans have become the dominant species world-wide. ${ }^{2}$ To learn how to live sustainably on this earth, we will have to change our behavior, our economies, our technologies, and our social systems. Otherwise, many fear a widespread ecological collapse; even the more restrained voices conclude that we face an era of dramatic, expensive and painful adjustments with an enormous decline in the quality of life for most of us. Yet if change of this magnitude is needed, and to this point not much in evidence, what is the role of law in creating the change that we must have to get to a sustainable future on this finite planet?

While it is easy, and to a degree accurate, to think of law as a traditional discipline more concerned with protecting the existing economic, social and technological systems rather than transforming them, in this book Capra and Mattei sketch out a vision of another legal system, one that responds to the demands of living sustainably on a finite planet. It is, of course, a legal system vastly different from what we have now. In Section 1 below, this comment will first review and discuss the new system-"ecolaw"- they envision.

Next, in Section 2, I will survey their fascinating review of the history of scientific thought and its parallels to the history of legal thought. Here, their core argument is that the two previously moved along parallel conceptual paths historically but, as science has changed from a mechanistic to a networked understanding of the world in the last two centuries or so, law has failed to make this move. The result, they argue, is a legal system increasingly out of touch with the intellectual currents of the times as well as one that cannot meet the ecological need of the era.

Yet how is this new "ecolaw" system to come about? After all, revolutions in a legal system are rare, particularly ones not forced or accompanied by major social and political transformations. While this book does not offer a carefully detailed scenario, it does present some interesting ideas that sketch out visions

\footnotetext{
1 Capra and Mattei (2015).
}

2 For an introduction see the Working Group on the Anthropocene of the International Union of Geogological Sciences, http:/quaternary.stratigraphy.org/workinggroups/anthropocene/ visited 2/1/2016. 
of where the influence for change may come and how the current system might evolve into what they see that we need. These will be noted throughout.

\section{Eco-Law}

The Capra and Mattei's conception of eco-law is of a fundamentally different legal system and their project here is to explain what it is and why it is needed. The key idea here is that the legal system must change so that it can respond to the requirements of humans living on a finite planet in the Anthropocene. While they do not emphasize it, with present and anticipated population growth worldwide, these requirements will become greater and the need for such fundamental change will surely, in their view, become even more pressing. Eco-law will be a fundamentally changed conceptual structure for law, with different goals and means for pursuing them. At its core, this is a utopian call for a grand new legal system, to achieve grand new objective. ${ }^{3}$

In order to foster living sustainably on the planet, eco-law must seek to become regenerative of ecosystems, in contrast to the present systems which emphasize extraction and exploitation which are often destructive to them. To foster regeneration of ecosystems, the legal system must change its emphasis from private property to focus on commons property and community values and institutions. Collective rather than individual rights will be key. Networks of people in communities for determining use of common property will replace both traditional ideas of private property and individualism as well as traditional legal institutions for pursuit of social control. The process of then creating and managing these new rights and institutions, "commoning" in the author's terms, will become the way that law functions and is implemented. The result is a completely restructured system of legal institutions, rights and responsibilities. ${ }^{4}$

The transition to this new system, here called a movement "from capital to commons", rests on 3 strategic objectives. ${ }^{5}$ First is disconnecting law from power and violence. In this conception law becomes a function of community driven networks and groups, operating by consensus from the bottom up rather than operated authoritatively from the top down. Presumably it will grow and develop organically. In the author's broad brush utopian vision, little more is said about how law will be made and implemented this way, although perhaps to raise the question is to ask for a different vision than they are now providing.

3 Capra and Mattei, Ch. 8.

4 Capra and Mattei, Ch. 10.

5 Capra and Mattei, Ch. 8 
This compact and focused book is a call for a new order and does not develop extensive analysis of the process of getting there.

The second objective is equally bold. Community must be made sovereign, and this sovereignty must replace our present sovereignty of individual ownership. Here again, community is central and the individual is important as she serves this goal. This is essential, they argue, to make the legal system regenerative of ecosystems rather than exploitative of them- the third grand objective. In this new system, private ownership does not necessarily disappear, but it exists only to serve this community sovereignty and regenerative goal. The premise is that community ownership will be concerned with preserving and advancing ecosystem health. This, again, is “commoning” in the author's terminology.

In this conception, the technical form of legal ownership is not key. Rather, the critical element is the use to which resources are to be put. ("Communizing".) ${ }^{6}$ Their most interesting discussion of this point notes that, in the past, society has owned and managed much more property as commons than it does today, even in a legal system recognizably similar to what we have today. Moving forward from this historical view, under eco-law the right legal form of ownership is to be determined by what serves the "commoning" purpose, regenerating the commons. Here, eco-law will emerge gradually through self-organized communities, growing from the bottom up. Of course, new human laws will be needed to allow and support such a transition.

An example may help here. Capra and Mattei offer the recent history of Teatro Valle as it has come to operate as a commons. ${ }^{7}$

In Rome, the beautiful and antique Teatro Valle, a jewel of eighteenth century architecture, was occupied by a crowd of artists and entertainment industry workers as a reaction against a privatization project. Since the theatre was declared a commons in June 2011, it has offered hundreds of hours of cultural, political and artistic entertainment, on a needs basis, outside the recognition of any state law....[T]he occupiers have kept the place open, functioning and clean.... [I]t has worked in a fully open, consent-based participatory fashion for more than three years. [citations omitted] ${ }^{8}$

It is now organized as a "commons foundation", in legal function an entity recognizable as a trust, with about six thousand members. This "constituent effort to create a legal system of the commons, legitimized by actual struggles from the bottom up" has spawned a group of similar efforts supported by "an itinerant group of jurists.” Of course, existing legal institutions and practices will

6 Capra and Mattei, Ch. 9

7 Capra and Mattei, pp.157-159.

8 Capra and Mattei, p. 157. 
not fit well with such examples and practices "because of the structural imbalance that favors private interests over the public good." And Teatro Valle exists and continues despite the fact that it does not really have a legal status. Yet, in the author's view, these efforts for commons struggles "create a legal literacy" which is spread across all such struggles.

Two other examples, both involving publicly owned municipal water systems, are offered briefly as further illustration. ${ }^{9}$ In each case, Naples and Paris, the public ownership was instituted in response to efforts to privatize what the founders thought should be a system "owned and managed by the people and the workers in the interests of the whole community and future generations." In each case, the board of directors is bound by this public purpose and it is precluded from making a profit. Market generated profits are not the measure of success of the ventures; rather, the goal is achieving a sustainable water supply, including conservation based on widespread eco-literacy. In these and other cases, private property and traditional legal forms and institutions may have a role to play, but only as they are part of this eco-legal system and serve its purposes.

The claim here is that "eco-law" is required to respond to the real resource requirements of life on the planet in the human dominated "Anthropocene". The author's focus here is on the eco-justification for communitarian ownership and management of resources. Consider the author's distinction of the advantages of such a community ownership form in the two water systems. "The traditional corporate form, whether public of private, is designed to sell as much water as possible [in order to increase profits]. In contrast, if water is treated as a commons, the main purpose is to save as much of it as possible by investing in community eco-literacy and reducing waste. The market is ill equipped to monitor the reach of this living corporate purpose of saving water and reducing the sell(sic)."10

The key claim for eco-law here is that it will support and lead to more sustainable ways to produce and consume, to live, because commonly owned resources, managed as the authors advocate, seek to use resources for a different goal. Ultimately, this claim will need much more elaboration and support to prevail. Certainly there are many historical examples of commonly owned resources, locally managed by consensus, having achieved a degree of sustainability. Of course, there are also counterexamples where commonly owned resources have been overexploited, used unsustainably, and squandered or lost. ${ }^{11}$ Commons property has been around for a very long time and the study of this is vast and deep. This book is a first statement of the theory, aimed as it

9 Capra and Mattei, pp. 164-65.

10 Capra and Mattei, p. 165

11 Hardin (1968). 
seems to be at a broad general audience, rather than a more specialized academic one, and this and other points must await further elaboration. The authors note "We still have a long way to go in elaborating the appropriate legal structures to run water, transportation, waste disposal, and other public activities as commons, but the examples of Naples and Paris suggest that such attempts, while difficult, are not impossible to achieve." I suggest that they also have much more work to do to support the eco-justification argument that their style of commons ownership will necessarily be more sustainable. How is the sustainability performance of such commons ownership working out in these and other contemporary cases to which they make general reference? How has it worked out historically? As eco-law grows and develops, are some characteristics supportive of better sustainability performance and some not, perhaps even in conflict with it. The answers to these questions await further work.

This communitarian based idea of legal, economic and other social organization is not new. In addition to the eco justification noted above, traditional consideration of community based common property has had to wrestle mightily with questions of historical experience, economic productivity, and personal freedom, among others, and there is not a general consensus on the answers. These broad questions about communitarian ownership naturally arise here as well and analysis of them must surely become part of the justification for eco-law on this basis as well. This book does not give substantial consideration to these questions. Fair enough, as this is not the task it has taken on. Developing the idea of eco-law is a big job, enough for one book. Of course, before eco-law is seriously considered for widespread adoption, further consideration of these traditional questions will also be essential.

However, beyond the ecosystem justification for eco-law, the authors support it from a completely different perspective. The first several chapter of the book provide an extended and most interesting survey of the dominant paradigms of thought in science and in law. The argument is that, while the two have historically changed in parallel fashion, the conceptual structure in which science thinks has changed in the last two centuries, and law needs to make a similar change. This change will also point toward a legal structure based on eco-law.

\section{Science and law: Changing conceptual paradigms point toward eco-law}

Science has changed its grand conceptual paradigm in the last two centuries, and, the authors argue, law needs to change this way as well; further, doing 
so will be an important part of the move to eco-law. The argument here is a grand conceptual tour de force, looking first at development and change in the large, dominant paradigms of scientific thought and then comparing these to the dominant paradigms in legal thought. Both begin with the grand paradigm of kosmos as the understanding of what the world is and how it works, and then both change to a grand conception of machine as a replacement. ${ }^{12}$ In science, this transition from "kosmos to machine" grew, from the Greeks to Newton, and came to be science's key idea of understanding the world at that time. The conception proved to be fruitful and useful and a vast amount of new learning and understanding was based on it. The scientific revolution, the Newtonian conception of the world machine, and the idea of "laws of nature" were vastly benefitted and advanced. "Thus, for scientists of the eighteenth and nineteenth centuries, the tremendous success of the mechanistic model confirmed their belief that the universe was a huge mechanical system, running according to the Newtonian laws of motion."13

Along with this idea ran a parallel development in western legal thought as the dominant paradigm shifted from "commons to capital". The argument here is that, during roughly the same time period, western legal thought shifted from primary emphasis on commonly owned property and resources to an emphasis on individual ownership, property rights, and the protection of these rights with ideas of natural law.

In the transition to modernity, Western legal scholars began to conceive of the law as an aggregate of discrete component parts governed by strict natural laws of individual reason. The ancient holistic vision of the world as kosmos, of the earth as a generous gift of God to humankind as a whole and an abundant commonwealth collectively accessible by all, was replaced by a humanist emphasis on the individual and human reason, which resulted in a Mechanical legal vision know as rationalist natural law. ${ }^{14}$

As a result, commons based institutions were changed into private property, and eventually into capital, with private ownership being the most important and largely dominant jurisprudential concept. State sovereignty became the mechanism for governing the privately owned component parts. In the author's most interesting telling of this development, the rise of legal professionalism, the enclosure movement, and as noted, the importance of state sovereignty to

12 Capra and Mattei, Ch. 2, "From Kosmos to Machine".

13 Capra and Mattei, p. 42

14 Capra and Mattei, p. 45, citations omitted. 
protect individual rights, all feature prominently. The result is anthropocentric natural law in the age of reason, with the broad social objective of distributive justice as an unfortunate casualty along the way.

In this argument, mechanistic science and rational methodology provided a useful analogy for change in law from relational rights, those that predominate in a commons, to individual rights which must then be backed up with "modern" legal institutions enforced and guaranteed by expanded ideas of national state sovereignty. ${ }^{15}$ This is, it is argued, completely consistent with the enclosure movements at home and imperial plunder and exploitation abroad. Technically, legal thinking dropped its distinction between common property and property no one owns, and the latter became property that can be claimed and then individually owned. The argument is not that the change in scientific thinking caused a change in legal thought, but rather that it provided a useful analogy and well worked out conceptual structure which supported the parallel development. And this was even more true at a time when educated people tended to be schooled in and knowledgeable about of both science and law. Indeed, it was not unusual for the same person or people to be leading figures in each area.

Further, the emergence and eventual growth of "political economy" into modern day economics was both aided and comfortably consistent with the changing scientific paradigm.

At the beginning of the nineteenth century, economists began to systematize their discipline in the continuing attempt to cast it in the form of a science.... In the subsequent evolution of economic thought, mainstream economics (as well as the associated legal framework) remained deeply rooted in the Cartesian-Newtonian paradigm, and today the approach of contemporary economics is fragmentary and reductionist. Economists generally fail to recognize that the economy is merely one aspect of a whole ecological and social fabric. Instead they treat all goods equally, without considering the many ways in which goods are related to the rest of the world, to the conditions of production, and to class composition. All values are reduced to the single criterion of increasing the size of the pie (wealth maximization.) ${ }^{16}$

Simultaneously, and not merely coincidentally, the development of the corporations as a "legal person" and the critical importance of this conception took place. When this paradigm became fully developed, it is argued, we see the modern legal system and the economic rationale and justification for it.

What happened next in scientific thought is then a crucial turning point. During the nineteenth century, it gradually evolved from a dominant paradigm

15 Capra and Mattei, Ch. 4.

16 Capra and Mattei, p. 81. 
of "machine" to a dominant paradigm of "networks". ${ }^{17}$ Science was advancing and much of the new learning did not fit well in the Newtonian machine. "[S] everal developments in nineteenth-century science - the theory of evolution, the investigation of electric and magnetic phenomena, and thermodynamics - made the limitations of the Newtonian model apparent and prepared the way for the scientific revolutions of the twentieth century." 18 The romantic movement in philosophy, art, and science emphasized the organic whole, rather than the component parts and directly confronted the classical machine analogy. In contrast to the earlier idea of focus on the individual parts of the "machine", here a key idea is that the whole is more than the sum of its component parts. Evolution theory in biology, as well as the study of forces and fields in studying electricity and magnetism, simply could not be well described by the Newtonian machine paradigm and they required a new conceptual way of thinking. Further developments in physics, "that at the sub-atomic level, the world could no longer be decomposed into independent elementary units", offered perhaps the greatest "shock" to the machine paradigm. Systems thinking in the life sciences, including conceptualizing the new discipline of ecology, also provided fundamental support for this change. The combined result has been systems thinking which focuses on living networks, in which, to repeat, the whole is greater than the sum of its parts. In networks, relationships and forces are key to understanding; a static system of rules based on the paradigm of a static machine made up of determined component parts simply won't work very well.

After this shift in scientific thought from the machine to the network, it is only a short, easy step to look at social systems and their networks in the same way.

A framework to extend the systemic understanding of life to the social domain, and in particular to human laws, rests on the assumption that life has a fundamental unity and that different living systems exhibit different patterns of organization.... The network pattern, in particular, is one of the very basic patterns of organization in all living systems. ${ }^{19}$

Communication is key in social networks, providing the energy which makes them self-generating. Social networks mostly don't produce material products, but rather interactions and communications within and between them. These form multiple feedback loops that eventually "produce a shared system of beliefs, explanations, and values, also known as culture, which is continually sustained by further communications... [through which] individuals acquire

17 Capra and Mattei, Ch. 5.

18 Capra and Mattei, p. 87.

19 Capra and Mattei, p. 97. 
identities as members of the social network."20 In this view, social systems can also most usefully be understood as networks rather than machines.

The argument is that, without viewing the world as networks, including social networks, we will not see it clearly and understand it well. This is, then, the great loss of the legal system as it has remained stuck in the "mechanical jurisprudence" and the "mechanistic trap" based on its failure to move beyond the paradigm of the machine to the network. ${ }^{21}$ Rather, legal thinking is stuck with the "machine" paradigm, when the "network" paradigm is what is needed and available. Ecolaw, based on a new "network" jurisprudential paradigm, is what is now needed.

Legal thinking is stuck in this traditional mechanistic paradigm despite pressures for change from both evolutionary thought and romanticism; these have been unsuccessful in displacing the mechanistic idea of law from its central position. We got here, the authors argue, with the development of a mechanical legal system based on the idea of a determinate natural law, articulated in a fixed body of rules, developed and applied by a core of specialized professionals. Legal evolution was effectively portrayed as the necessary ingredient in a four stage process of economic and social development, from hunter-gathers to pastoral herders and cattle breeders, then on the agricultural farmers, and finally commercial producers and consumers. This "evolutionary process" provided an appearance of consistency with developing thinking in science while preserving the mechanistic idea with private property as its core. And of course, this rationale was much more palatable when offered by an increasingly professionalized corps of law interpreters and appliers whose professionalism and distance served to insulate it from critique of a broader gauged social perspective.

Yet the core argument about causation is not primarily historical or philosophical, but rather instrumental and economic.

The resilience of the mechanistic approach in human laws is due to its invaluable service to the needs of nineteenth-century capitalism...A systematic vision of the nature of law as a living network of communities allowing for the "emergence" of new legal forms in order to sustain the survival or our planet is still to come. ${ }^{22}$

This leads to the author's "mechanistic trap" in which law becomes an autonomous discipline of the actions of legal institutions in which human actors are no longer able to control to achieve social objectives. Several unsustainable and unjust characteristics are then argued to result.

20 Capra and Mattei, p. 98.

21 Capra and Mattei, Chs. 6 and 7.

22 Capra and Mattei, pp.101-02. 
The trap leads so narrow pursuit of the short term bottom line performance of economic actors, giving them seriously flawed incentives. For example, outsourcing to the lowest price supplier, typically "from advanced industrial companies to countries where workers and the environment are exploited beyond any reason". ${ }^{23}$ The 2013 example of Rana Plaza collapse which killed over 1100 poor workers in Bangladesh provides a vivid example. The work was being done for well-known western brands, but the legal structure of outsourcing lets them reap large profits while contracting through intermediaries to evade responsibility for the tragedy. Indeed, the authors argue, the focus on profit maximization to some degree requires such conduct. "Worldwide, there are many such examples of corporations relentlessly pursuing shareholder interest, working as legally determined machines, and externalizing social costs."

Global capitalism, a network of essentially unregulated capital flows "outside any ethical framework", is another unfortunate result. This, in turn, leads to increasing social inequality and exclusion, increasing poverty, as well as faster and more complete deterioration of the environment. What then follows is, it is argued, the current situation in which governments are weaker than the strong corporations they might otherwise try to control. When the system developed, control of strong governments over corporations to protect relatively weaker people and economic interests was a goal. Today the balance has shifted, as is illustrated with examples from international law. Consequently we now have the vast social impact of business decisions which have no check for legitimacy, undercutting the democratic process through the influence of money in politics and the "revolving door" between government and business, and the ongoing economic and social exclusion of so many people from control or influence over decisions that affect their lives.

The result is a legal ideology that not only cannot command socially optimal results, but may indeed perversely create incentives for bad ones:

The tight structural connection between private property and unsustainable practices and short term extraction explains the difficulty of exiting the mechanistic trap. The law severely limits out ability to take into account the effect of current economic decisions on future generations or the true costs of unsustainable activities for the community at large.... Any attempt to put public interest over private ownership faces a high burden of proof, because scores of economists, jurists, and pundits immediately rush to protect the sanctity or private property and the unlimited freedom of an owner. [citations omitted].... Above all, property law protects corporations - all powerful, eternal institutions that are structurally incapable of generous or ethical behavior. ${ }^{24}$

23 Capra and Mattei, pp.111-112.

24 Capra and Mattei pp.124-125. 
The author's solution, as discussed more fully above in Section 1, is a new conception of eco-law. Their primary justification is the need to achieve a more sustainable world, although along the way recurrent themes of economic and social justice, inclusion, human rights and genuine democracy are certainly included.

While one can quibble with the breadth of the claim - there is in fact quite substantial regulation of corporate labor, financial, business and environmental conduct - the broad thrust of this claim rings true. In today's globalized economic world, with compromised political institutions in many countries, large multinational business operates with broad discretion and limited effective outside control. While there is much talk of corporate pursuit of sustainability, based either on market pressure or genuine commitment or both, the reality is that on balance they and all of society continue to behave in unsustainable ways. A strong case can be made for eco-law on these sustainability grounds, and to align legal thought with modern scientific thought.

\section{Conclusion}

The authors thesis is, then, that eco-law is needed to live sustainably on the planet, and that achieving it will bring the dominant paradigm of legal thought in line with the new dominant paradigm of scientific thoughts. The emphasis is on networks and relationships, rather than mechanistic working of individually analyzed parts. Law will emphasize these by putting communitarian values at the core, limiting private property to where it serves these values. The system will operate by consensus and be divorced from a state monopoly of power or violence. And it will emphasize pursuit of sustainable living on the planet, regenerating resources on balance, rather than exploiting them. While the authors give only some glimpses of how this will come about, they seem to imply that it will grow organically, over time, and that the infrastructure of legal institutions, rules and incentives will develop along with it.

This sketches a grand utopian vision of how law and the world could work. As with many utopian visions, it is most attractive and inspiring when considered on its own terms. I have offered a number of comments on specific questions that are presented, particularly those concerning the real sustainability and economic performance of commons based systems, and these do not need repeating here. To offer eco-law as a full blown idea of how the world would work, much more is needed. Yet that is asking for more than I think the author's intended to provide in this first sketch. As a sketch, the book offers many new ideas, particularly about the parallel development of the dominant paradigms in scientific thinking and in 
legal thinking. As a sketch, it serves both as a rallying cry for those already committed to its values and goals, as well as a jumping off point for further thought and analysis for all interested in these questions. At this point, again as a sketch, it is not likely to convert many skeptics and opponents.

\section{References}

Capra, F., \& Mattei, U. (2015). The ecology of law: Toward a legal system in tune with nature and community. Oakland, California, USA: Berret-Koehler Pubs.

Hardin, G. (1968). "The tragedy of the commons". Science, 162, 1243. 